\title{
Educação física escolar em Brasília, na década de 1960
}

Ingrid Dittrich Wiggers

\begin{abstract}
Resumo: A pesquisa teve como objetivo analisar atividades de educação física presentes no currículo original da Escola-Parque de Brasília, na década de 1960. Utilizamos como referência teórico-metodológica a história cultural, enfocando o tratamento de fontes primárias, como fotografias, documentos oficiais, entrevistas e publicações da época. As fontes evidenciaram que a educação física se realizava na forma de recreação, esportes, competições, desfiles e aulas, ocupando lugar de destaque na cultura escolar analisada. As atividades de educação física faziam parte de um projeto educacional inovador, cuja concepção pedagógica, currículo ampliado, turno integral e arquitetura especial valorizavam uma educação do corpo. Palavras-chave: Educação Física; Educação; História; Fotografia.
\end{abstract}

\section{EsCOLA-PARQUE DE BRASÍLIA}

A Escola-Parque é um exemplo da peculiaridade de Brasília, uma cidade caracterizada pela estética modernista do desenho urbano e da arquitetura monumental. Como parte do planejamento de Brasília, Anísio Teixeira concebeu um sistema educacional inovador, de modo integrado a outros setores, como cultura e saúde. Conforme destacou em entrevista a Profa. Stella dos Cherubins Guimarães Trois 1, “[...] uma das exigências do Congresso Nacional para a instalação da nova capital no Governo do Presidente Juscelino Kubitschek era que houvesse um sistema educacional de qualidade". $\mathrm{O}$ fundo em branco de uma cidade em construção - a futura capital - oferecia o espaço político perfeito para a implantação do sistema

\footnotetext{
* Licenciada em Educação Física pela Universidade Federal de Santa Catarina. Mestre em Educação Física pela Universidade Federal de Santa Maria. Doutora em Educação pela Universidade Federal de Santa Catarina (2003). Professora da Faculdade de Educação Física da Universidade de Brasília (UnB), desde 2007. Membro do "Núcleo Infância, Comunicação, Cultura e Arte", sediado na UFSC. E-mail: ingridwiggers@gmail.com

${ }^{1}$ A Profa. Stella dos Cherubins Guimarães Trois foi a primeira diretora da Escola-Parque, localizada na entrequadra 307/308 Sul, entre 1960 e 1963. A entrevista foi realizada e transcrita por Maria de Souza Duarte, em 1981.
} 
educacional pioneiro, pretendido como modelo para o Brasil, no qual a escola era vista como uma "máquina de democracia", principalmente porque Brasília estava sendo construída para que pudesse funcionar como catalisadora da integração do país, como símbolo do nacional-desenvolvimentismo.

Com base na experiência de educação integral de Salvador ${ }^{2}$, que já era reconhecida internacionalmente, foi confeccionado o planejamento do sistema escolar de Brasília ${ }^{3}$. O programa foi estruturado em três grandes níveis: educação primária, educação média e educação superior. A educação primária seria oferecida em "Centros de Educação Elementar", cada um formado por Jardins de Infância, Escolas-Classe e Escolas-Parque. A educação intelectual sistemática e tradicional de estudantes entre 7 e 14 anos caberia às Escolas-Classe. Visando completar a tarefa destas, seria construída, para cada grupo de quatro Escolas-Classe, uma Escola-Parque, com a finalidade de promover o desenvolvimento artístico, físico e recreativo da criança e ainda sua iniciação para o trabalho ${ }^{4}$. A EscolaParque compreenderia biblioteca, museu, pavilhão para atividades industriais, espaço para recreação, conjunto para atividades sociais (música, dança, teatro, clubes, exposições), refeitório, setor administrativo e pequeno prédio residencial para menores sem família ${ }^{5}$. Assim, a expressão "parque" fora usada para designar um parque de escolas, ou seja, uma rede de edifícios ligados entre si, com funções complementares e dentro da mesma área (TEIXEIRA, 1961).

O plano de construções escolares da nova capital levou em conta a configuração urbanística da cidade. Nessa perspectiva, considerando que uma quadra do Plano-Piloto abrigaria cerca de 2.500 a

\footnotetext{
${ }^{2}$ Em 1950, foi inaugurada a primeira Escola-Parque, em Salvador, no bairro da Liberdade, por Anísio Teixeira, na condição de Secretário da Educação da Bahia, denominada de Centro Educacional Carneiro Ribeiro.

${ }^{3}$ Além de Anísio Teixeira, então diretor do Instituto Nacional de Estudos Pedagógicos (INEP) contribuíram diretamente para a formulação do "Plano educacional e médico-hospitalar", de 1959 Paulo de Almeida Campos e Nair Durão Barbosa. O trabalho foi coordenado pelo Dr. Ernesto Silva, um dos diretores da Companhia Urbanizadora da Nova Capital do Brasil (NOVACAP).

${ }^{4}$ Trata-se de um modelo fundamentalmente baseado na filosofia pragmatista de John Dewey (EUA). No plano nacional, esse sistema de ensino levou em conta a concepção escolanovista, pois Anísio Teixeira foi um dos co-autores do Manifesto dos Pioneiros da Educação Nova, publicado em 1932, que por sua vez, recebeu influência do pragmatismo de John Dewey.

${ }^{5}$ Essa residência foi a única parte do projeto que não se construiu.
}

Movimento, Porto Alegre, v. 17, n. 01, p. 137-157, janeiro/março de 2011. 
3.000 habitantes, planejou-se para cada quadra um Jardim de Infância para cerca de 160 crianças e uma Escola-Classe para 480 estudantes. A partir do cálculo desta população escolarizável, seria construída uma Escola-Parque para cada quatro quadras residenciais, visando atender, em turno contrário ao da Escola-Classe, cerca de 2.000 alunos.

O objetivo do plano foi atingido com a fundação da primeira Escola-Parque de Brasília, instalada entre as Superquadras 307 e 308 Sul e coincide com a inauguração da capital, em 1960. Essa unidade, em funcionamento até os dias de hoje, representa o marco de implantação do sistema educacional da capital emergente. As primeiras Escolas-Classe por ela atendidas foram a $108 \mathrm{Sul}$ e a 308 Sul. Em 1961, incluiu-se a Escola-Classe 107 Sul e, em 1962, a Escola-Classe 106 Sul, compondo-se o " $1{ }^{\circ}$ Centro de Educação Elementar", em Brasília, para atendimento em turno integral.

Para além da importância local - é parte significativa do empreendimento educacional do centro político da nação - a Escola-Parque tem grande relevo nacional. A literatura investigada indicou que o projeto idealizado por Anísio Teixeira se configura no percurso da educação brasileira como uma expressão paradigmática (PEREIRA; ROCHA, 2005). Ademais, o estudo se faz oportuno porque em 21 de abril de 2010 a cidade comemorou o jubileu, o que anima o fortalecimento de seu patrimônio ${ }^{6}$. A pesquisa teve como objetivo analisar atividades referentes à educação física presentes no primeiro currículo da Escola-Parque de Brasília, na década de 1960, por meio de imagens fotográficas, documentos oficiais, publicações da época e entrevistas ${ }^{7}$.

\footnotetext{
${ }^{6}$ A Escola-Parque 307/308 Sul foi tombada como Patrimônio Histórico do Distrito Federal, em 2004, pelo Decreto no 24.861, de 04/08/2004, publicado no Diário Oficial do Distrito Federal (DODF) em 05/08/2004, da Diretoria de Patrimônio Histórico e Artístico do Distrito Federal (DEPHA). Contribuiu sobremaneira para esse processo a iniciativa da Associação de ArteEducadores do Distrito Federal, que protagonizou o "Fórum Escola-Parque, Patrimônio da Educação Brasileira", realizado entre 12 e 14 de agosto de 2002.

${ }^{7}$ Esse estudo integra o projeto de pesquisa "Educação Básica Pública do Distrito Federal: origens de um projeto inovador", coordenado pela Profa. Dra. Eva Waisros Pereira, da Faculdade de Educação da UnB. Contamos com o apoio do CNPq, por meio de bolsas de iniciação científica. As bolsistas de iniciação científica Mariana Ziloti Frazzi (UFSC) e Isabela Ribeiro Marques $(U n B)$ colaboraram em etapas anteriores dessa pesquisa. Agradecemos ainda à unidade da Rede CEDES da UnB.
} 


\section{As FONTES PESQUISADAS}

Um álbum que reúne duzentas e vinte e seis fotografias da Escola-Parque 307/308 Sul, do período compreendido entre 1960 e 1972, constituiu nossa principal fonte de evidências históricas. Trata-se do período inicial de sua trajetória, que foi marcado pela inauguração, em 1960 e pelo ato que estabelece novos parâmetros para o seu funcionamento. Referimo-nos ao documento "A EscolaParque em Brasília" (DISTRITO FEDERAL, 197), cuja elaboração deu-se em atendimento ao imperativo da Lei No 5.692/71 e da Resolução No 01/74, do Conselho de Educação do Distrito Federal (CEDF). Esse ato representou uma ruptura com o conceito original da instituição, pois a Escola-Parque teria deixado de ser, a partir dele, a representação da "universidade infantil" pensada por Anísio Teixeira, circunscrevendo-se dali para frente ao atendimento das disciplinas de Educação Física e de Educação Artística.

A perspectiva da história cultural embasou o trabalho, privilegiando o enfoque no tratamento de fontes primárias. Nessa nova forma de pensar a história, as fotografias se situam como fontes relevantes, pois os registros "[...] aparecem também sob as mais variadas formas como escritos, objetos, palavras, música, literatura, pintura, arquitetura, fotografia" (VIEIRA; PEIXOTO; KHOURY, 1998 , p. 13). Isso porque analisar a história é pensar um tempo passado que pode ser identificado por vestígios que resistiram à dinâmica social. Vestígios, ressalve-se, são partes de um todo, que sabemos não poder reconstruir plenamente (BENJAMIN, 1987).

Para Souza (2001), o principal obstáculo ao uso de imagens como fonte de investigação histórica é a sua interpretação. Esta, para superar tal dificuldade, deve levar em conta que as fotografias são um produto da interação entre o fotógrafo, a tecnologia empregada na produção da fotografia e o objeto registrado. Leite (1993) adverte que a apreciação deve considerar os aspectos externos, que se referem às condições da produção da fotografia e os aspectos internos, que dizem respeito ao conteúdo da imagem. Em uma outra perspectiva, a imagem ofereceria um registro poderoso de ações temporais e dos acontecimentos concretos, tornando-se ela própria um fato social significativo.

Wovimento, Porto Alegre, v. 17, n. 01, p. 137-157, janeiro/março de 2011. 
A complexidade da análise de imagens é notada ainda pelos mecanismos implicados na sua recepção. Em outras palavras, ao mesmo tempo em que a fotografia produz um testemunho de um acontecimento, não deixa de ser ela mesma uma interpretação da realidade (LOIZOS, 2002).

A fim de ampliar o campo empírico, fizemos uso de documentos de cunho oficial, entre os quais destacamos os referentes a planejamentos educacionais para composição das fontes. Exploramos, ainda, transcrições de entrevistas com pioneiros da nova capital ${ }^{8}$, especialmente as colhidas por Maria de Souza Duarte, em $1981^{9}$. Por fim, consideramos como fontes primárias textos publicados pelo próprio Anísio Teixeira na Revista Brasileira de Estudos Pedagógicos. Nosso trabalho, portanto, caracterizou-se pela complementariedade de fontes e incorporação de diferentes linguagens para a construção de uma análise histórica do ponto de vista cultural e social, conforme sugerem, entre outros, Hobsbawm (1998) Le Goff (1995) e Thompson (2000).

\section{A educação FísICA NA ESCOLA-PARQUe}

Em visita à Escola-Parque 307/308 Sul, tivemos acesso ao seu rico acervo audiovisual, constituído de vídeos, fotografias e filmes nos formatos $16 \mathrm{~mm}$ e $35 \mathrm{~mm}$. Encontramos as fotografias cuidadosamente arquivadas em um conjunto de mais de cinquenta álbuns datados e legendados, sendo que o primeiro deles reúne duzentas e vinte e seis imagens, em preto e branco e coloridas, de 1960 a 1972. Tratam-se de fotografias que, originalmente, demonstram imperfeições de foco, de enquadramento e de luz, além de algum desgaste provocado pelo tempo que permaneceram guardadas, como se pode constatar nas reproduções que seguem. Provavelmente, são produtos da prática cotidiana da escola e não de uma ação profissional.

\footnotetext{
${ }^{8}$ Os primeiros imigrantes de Brasília, que participaram da empreitada histórica de construir e implantar a nova capital do país.

${ }^{9}$ Esta professora realizou pesquisa com o objetivo de registrar historicamente as experiências de educação por meio da arte, desenvolvidas em Brasília. Tal estudo reconstituiu entre mais iniciativas, fragmentos da memória da Escola-Parque, percorridos, então, cerca de 20 anos de sua inauguração, situando-a como parte do projeto cultural e artístico da nova capital (DUARTE, 1983). As transcrições foram cedidas pela própria pesquisadora.
}

Movimento, Porto Alegre, v. 17, n. 01, p. 137-157, janeiro/março de 2011. 
A primeira leitura das imagens evidenciou, de maneira geral, o currículo especial da Escola-Parque, que incluía, como vimos anteriormente, formação cultural abrangente, visando o desenvolvimento artístico, físico, recreativo, social e ainda a iniciação para o trabalho. As fotografias encontradas são vestígios da prática educativa relativa a uma concepção pedagógica desenvolvida por Anísio Teixeira ao longo de quarenta anos ${ }^{10}$, remetendo-nos a uma visão do que ocorria na escola e no interior do ambiente da sala de aula. Por conseguinte, as fotografias foram abordadas, nesse estudo, como representações da "cultura escolar" da instituição, que são, de acordo com Vinão Frago (1995, p. 68), o conjunto de [...] toda a vida escolar: fatos e idéias, mentes e corpos, objetos e condutas, modos de pensar, dizer e fazer."

O traço realístico das fotografias guardadas no primeiro álbum focou tanto situações cotidianas como eventuais. Embora a menor parte das fotografias do acervo tenha focado o dia-a-dia escolar, não podemos deixar de considerar que as de caráter eventual refletem atividades cotidianas. $\mathrm{O}$ que queremos salientar é a relação entre o cotidiano das aulas e os eventos escolares, como um critério de interpretação das imagens.

Em meio aos registros do amplo repertório de atividades, alguns se fizeram mais significativos para a presente pesquisa. Focamos, como supracitado, evidências da educação física escolar. Sob esse aspecto, pretendemos colaborar tanto para uma compreensão histórica da educação física escolar quanto para uma memória das práticas corporais no processo de escolarização, que se configuram, a nosso ver, como dois campos complementares.

Sob esse último aspecto, a educação do corpo na escola em tela se localizou em diferentes espaços, tempos e práticas educativas, incluindo aulas, atividades, dispositivos pedagógicos e manifestações de culturas corporais. O conteúdo das fotografias denotou ainda que a educação do corpo se realizava tanto em atividades

\footnotetext{
${ }^{10}$ Chegamos a esse número se partirmos de 1931, quando Anísio Teixeira passou a comandar a Diretoria da Instrução, no Rio de Janeiro, até 1971, ano de sua morte trágica, quando foi encontrado no poço de um elevador, na mesma cidade (VIANA FILHO, 2008).

Movimento, Porto Alegre, v. 17, n. 01, p. 137-157, janeiro/março de 2011.
} 
recreativas e esportivas, circunscritas ao âmbito da educação física, quanto em outras atividades, como as de caráter artístico, uma parte significativa do currículo da Escola-Parque da década de 1960. A interpretação das fotografias indicou, portanto, que aquela proposta pedagógica propunha a atividade corporal como dimensão explícita de escolarização, em uma perspectiva que foi além das atividades de educação física propriamente ditas.

A partir dos registros iconográficos, consideramos como cenas escolares da educação física sessenta peças, retratando brincadeiras, aulas de natação, competições esportivas e premiações, desfiles cívicos e de abertura de competições e ainda aulas de educação física, o que atingiu significativamente um quarto do número total de fotografias do álbum analisado. Segundo o currículo da época, a educação física seria constituída de "recreação, ginástica de solo, atletismo, ginástica moderna, grandes jogos e pequenos jogos e natação" (DISTRITO FEDERAL, 197-, p. 10). De acordo com esse documento, a Educação Física fazia parte do "estudo obrigatório" e era desenvolvida em três aulas por semana, sendo que os demais componentes da estrutura curricular, como é o caso de educação artística, educação religiosa, programas de saúde, artes industriais, técnicas do lar e técnicas de serviço, se limitariam a apenas duas ou apenas uma hora-aula semanal. Ambas as evidências, ou seja, tanto o grande número de fotografias como o documento curricular da escola, denotam a importância da educação física para o projeto sob análise.

Entre as situações classificadas especificamente como parte da educação física, abordaremos preliminarmente as brincadeiras ou a recreação. Em seu depoimento, a Profa. Stella dos Cherubins Guimarães Trois relembrou que as aulas da Escola-Parque 307/308 Sul se iniciaram no dia 20 de novembro de 1960, apesar de a escola ainda estar em construção e equipada com móveis improvisados. Por isso, o trabalho da escola, em caráter emergencial, começou, segundo a sua primeira diretora, no parque infantil. As brincadeiras, portanto, marcaram o início das atividades curriculares da Escola-Parque de Brasília. Contudo, não representaram um mero recurso para preencher os primeiros dias de aula daquela instituição. Notamos, 
também, que se fizeram presentes na continuidade de sua trajetória histórica. Nas fotografias analisadas, crianças foram mostradas brincando no pátio e também em espaços mais fechados, com ou sem a presença de um educador (Figuras 1 e 2).

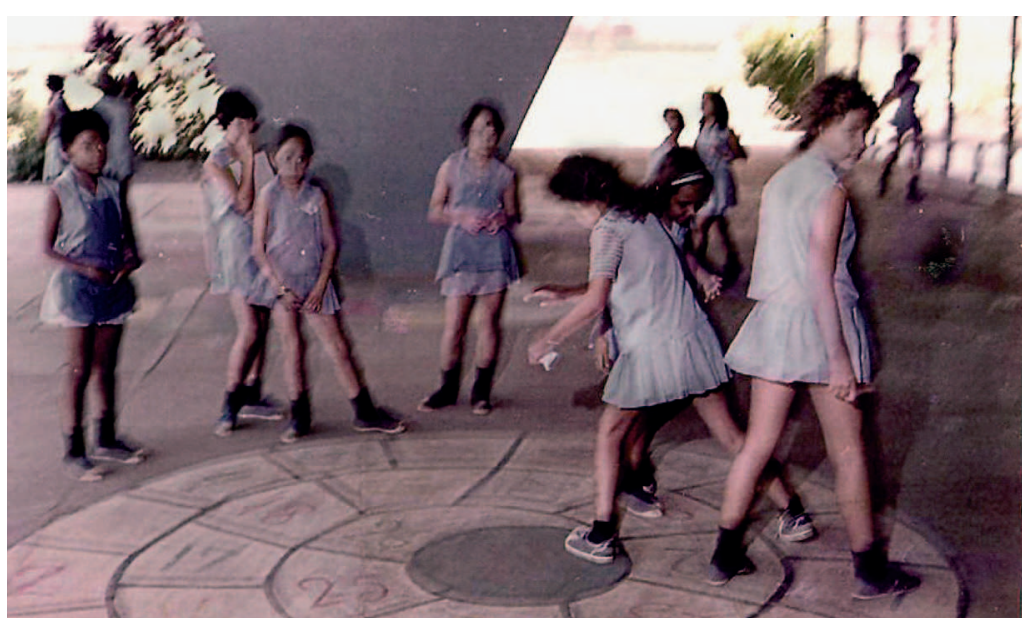

Figura 1 - Fotografia de brincadeiras na pérgula do prédio principal da escola.

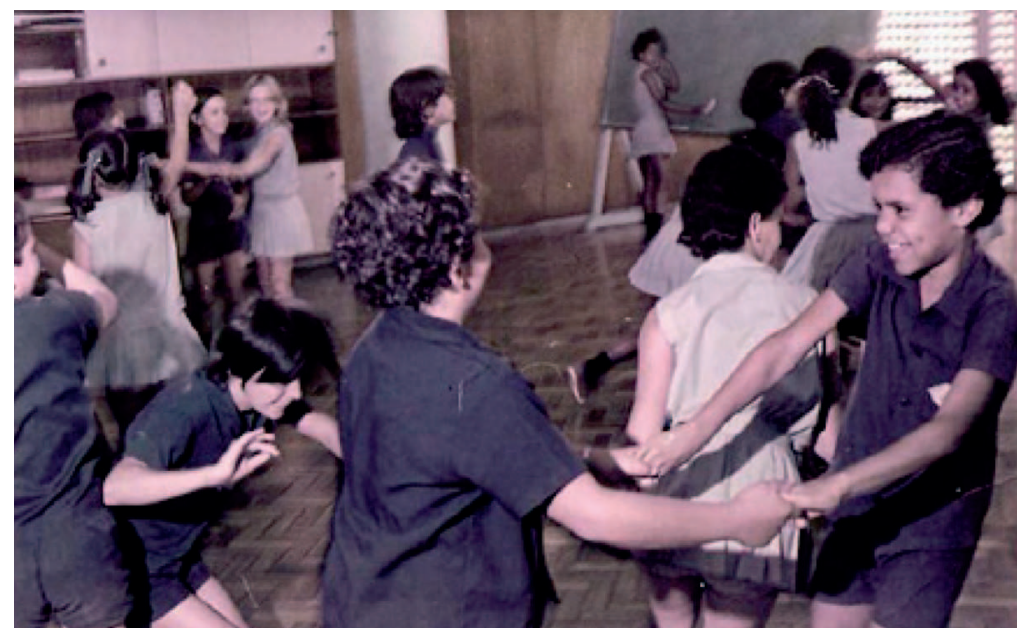

Figura 2 - Fotografia de brincadeiras na sala.

Wovimento, Porto Alegre, v. 17, n. 01, p. 137-157, janeiro/março de 2011. 
Conforme declarou Ernesto Silva ${ }^{11}$, as brincadeiras na EscolaParque não eram muito bem vistas pelos administradores da Companhia Urbanizadora da Nova Capital do Brasil (NOVACAP), o que teria provocado resistências internas desde o início. Alguns dos primeiros diretores diziam, em tom depreciativo, que a Escola-Parque não era uma escola, mas sim uma "casa de brinquedos". Diante do preconceito, o pioneiro não demonstrava se abalar e enfatizava $o$ caráter lúdico da proposta: "É para brincar mesmo. É para estimular, despertar vocações."

As brincadeiras como manifestações da cultura escolar ${ }^{12}$, evidenciadas nos registros históricos, podem ser interpretadas como sinais de uma nova educação, que a Escola-Parque buscava demonstrar. De acordo com fontes primárias pesquisadas por Oliveira (2006), as brincadeiras passaram a ser adotadas no processo de escolarização, no Brasil, a partir da passagem do modelo de escola isolada para o de escola graduada, cujo início teria sido marcado pela república, estendendo-se até os anos iniciais do século $\mathrm{XX}$. As brincadeiras foram validadas, naquele período, principalmente por seu caráter compensatório, prevenindo-se a fadiga escolar provocada pelas exigências de rigor e disciplina dos estudos em sala. Tornaram-se, assim, úteis para o processo de aprendizagem dos alunos.

Essa concepção parece ter evoluído para a noção de "recreação escolar" proposta pelo movimento de renovação pedagógica da educação brasileira, conhecido por Escola Nova, a partir do início do século XX. Para esse movimento, não se tratava de adotar a brincadeira no sentido grego clássico, ou seja, de recreação descompromissada. E nem de reproduzir-se nas escolas o jogo livre, próprio das brincadeiras de rua. Para a Escola Nova, a recreação, embora não tivesse o objetivo de proporcionar a aquisição de conteúdos, seria um instrumento fundamental do desenvolvimento físico, cognitivo e social das crianças. "Prioritariamente busca-se formar o corpo e,

\footnotetext{
${ }^{11}$ Entrevista concedida a Luciana de Maya Ricardo, em 2006, disponível no acervo do Grupo de Pesquisa "Educação Básica Pública do Distrito Federal: origens de um projeto inovador". 12 Para Julia (2001), as culturas infantis, que se desenvolvem no recreio escolar, por exemplo, são componentes da cultura escolar.
} 
conjuntamente, habilidades cognitivas, morais e sociais. Geralmente entram na categoria de jogos recreativos aqueles pertencentes ao folclore infantil, nos quais predominam a atividade motora (barramanteiga, corda) e rodas cantadas." (KISHIMOTO, 1999, p. 110). Sob esse ângulo, podemos interpretar a presença das brincadeiras na Escola-Parque como evidências de novas formas de corporalidade na educação escolar.

Para mais disso, a renovação pedagógica se fez presente naquela instituição, por meio de outra modalidade de prática corporal: o esporte. Nesse sentido, um aspecto incomum no cenário educacional do país atraiu o olhar do fotógrafo: aulas de natação. Seis imagens retrataram diferentes partes da aula: aquecimento corporal fora da piscina, atividades na borda e deslocamento na água.

$\mathrm{Na}$ primeira fotografia dessa série, aquela que registrou o "aquecimento", a professora aparece à frente da turma e ao seu lado um aluno-monitor demonstrando os gestos a serem executados. A turma encontra-se distribuída, no espaço, em provavelmente quatro fileiras, com cerca de oito alunos em cada uma delas, totalizando o número de trinta e duas crianças. É formada por meninos e meninas, que pode-se supor, entre oito e dez anos de idade. Além do traje de banho, nota-se que elas estão descalças, sem toucas para os cabelos e sem óculos apropriados. O exercício de flexão do tronco com pernas afastadas e estendidas é realizado por todos, mas em ritmo variado. Alguns participantes executam o movimento coordenadamente, mas outros com alguma dificuldade na manutenção da posição do corpo exigida para a flexão do tronco, contrabalançada por meio da flexão dos joelhos (Figura 3).

Wovimento, Porto Alegre, v. 17, n. 01, p. 137-157, janeiro/março de 2011. 


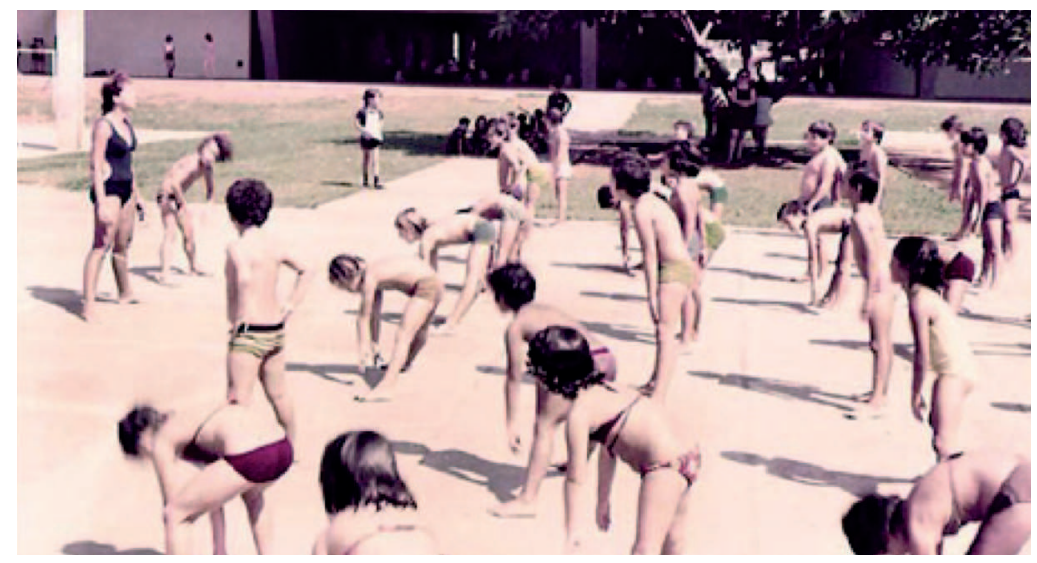

Figura 3 - Fotografia do aquecimento na aula de natação.

O esforço despendido pelas crianças no aquecimento fora plenamente compensado pelo momento da entrada na água e realização das atividades dentro da piscina. A concentração e o cansaço foram substituídos pela alegria e por uma expressão facial de contentamento e prazer, provocado pelo contato das crianças com o meio líquido (Figuras 4 e 5). Com efeito, de acordo com a primeira bibliotecária da Escola-Parque, Branca Rabello, uma enquete realizada nos anos iniciais de seu funcionamento evidenciou a natação como uma das três preferências das crianças, depois do cinema e da biblioteca ${ }^{13}$.

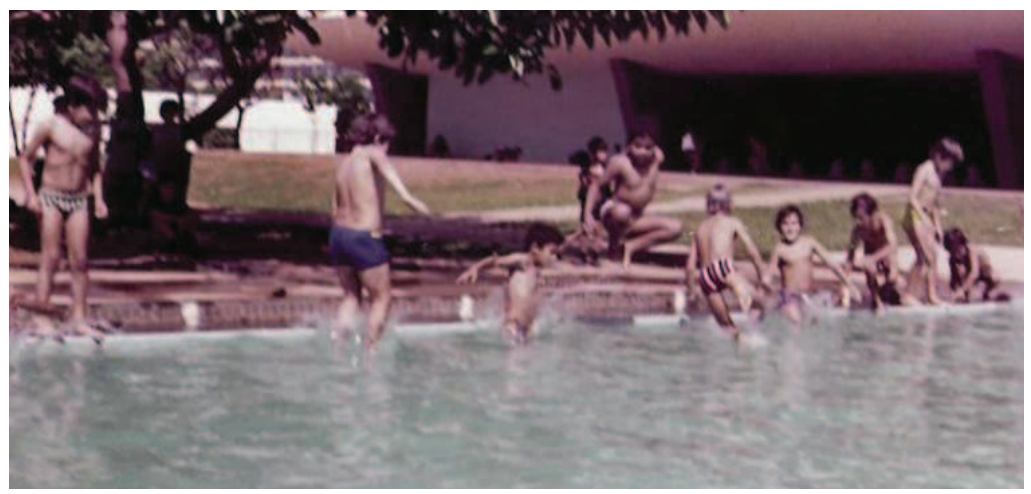

Figura 4 - Fotografia da entrada das crianças na piscina

${ }^{13}$ Esse depoimento foi colhido em entrevista realizada e transcrita por Maria de Souza Duarte, em 1981.

Movimento, Porto Alegre, v. 17, n. 01, p. 137-157, janeiro/março de 2011. 


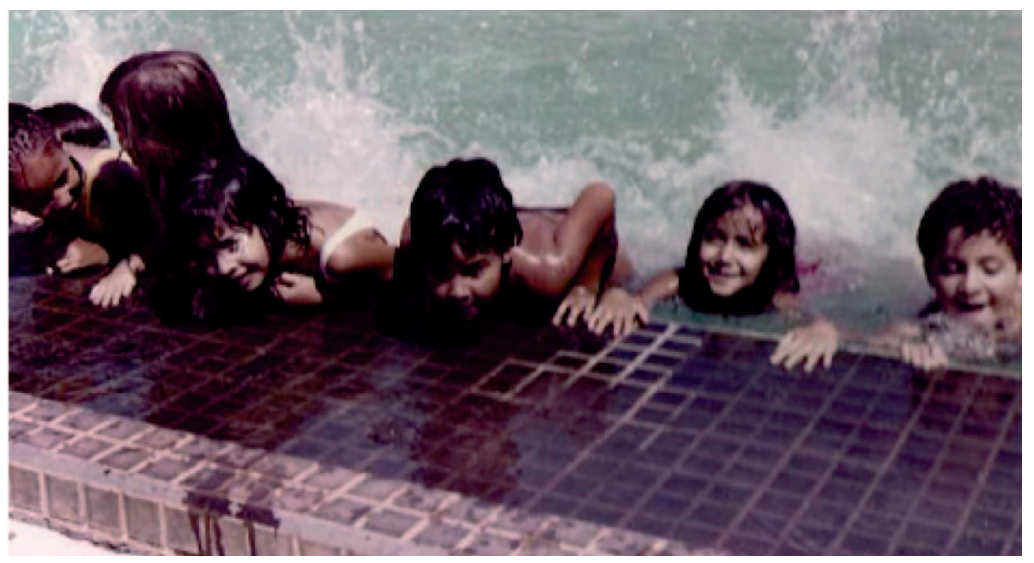

Figura 5 - Fotografia de atividades na borda da piscina

As aulas de natação deram ensejo a competições esportivas, conforme observamos no acervo iconográfico da década de 1960. Nessas imagens, durante os "Jogos da Primavera", estudantes competem em raias demarcadas, sob o olhar atento de um público formado provavelmente por familiares e pelos próprios alunos da escola (Figura 6).

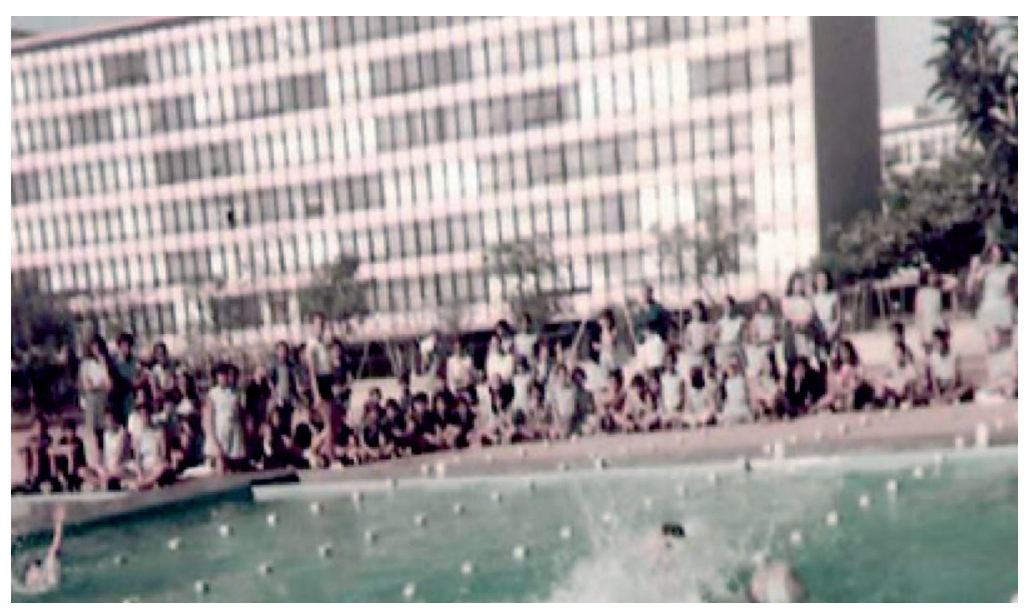

Figura 6 - Fotografia de competição de natação. Ao fundo se vê a fachada de prédios residenciais que contornam a área da escola

Movimento, Porto Alegre, v. 17, n. 01, p. 137-157, janeiro/março de 2011. 
Além de jogos e competições, outros acontecimentos, que podem ser incluídos no âmbito da educação física, se sobressaíram durante a análise histórica: os desfiles cívicos ou de abertura de competições escolares. A importância desses momentos na vida da Escola-Parque 307/308 Sul se evidenciou, para além do grande número de fotografias sobre o tema que guarda o acervo, pela sua repetida incidência em diferentes períodos da década investigada. Distintos grupos de imagens de desfiles registram sua ocorrência tanto externa quanto internamente aos limites do pátio da escola. Em ambas as situações, um público numeroso costumava prestigiálos, fazendo desses eventos importantes acontecimentos na cultura da cidade. Destacam-se as cenas localizadas na Avenida W3 Sul, que passa em frente à escola, que teria sido palco de muitas dessas apresentações. Para afirmar os desfiles como eventos culturais significativos, nota-se nas fotografias o cuidado com a indumentária e os adornos, como cartazes e faixas, que certamente exigiram esforço e dedicação para sua preparação (Figuras 7 e 8).

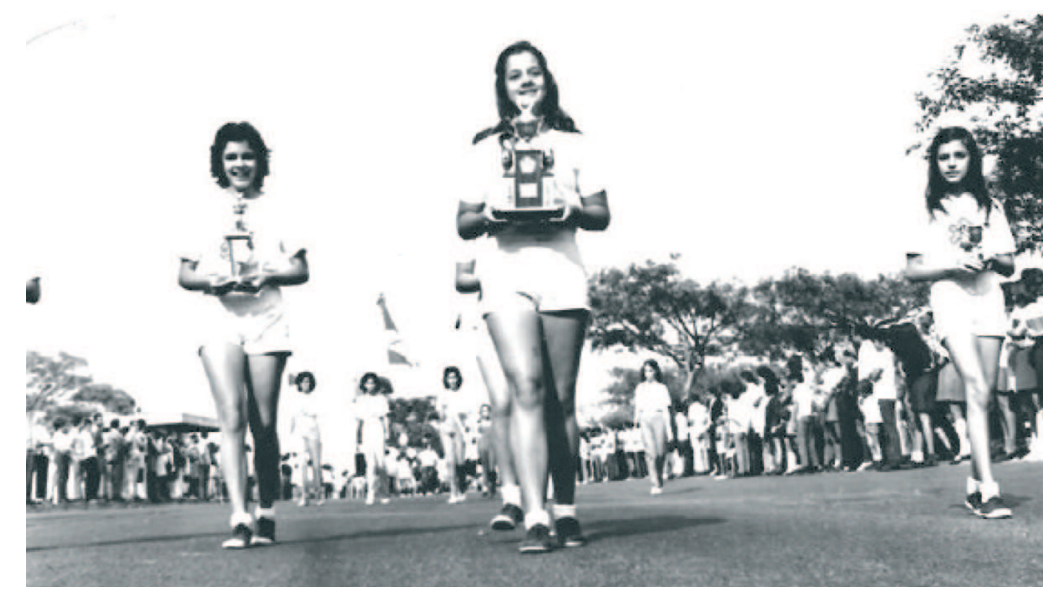

Figura 7 - Fotografia de desfile de estudantes na Avenida W3 Sul. O público mantém-se nas calçadas, respeitosamente, sem necessidade de uso de cordões de isolamento 


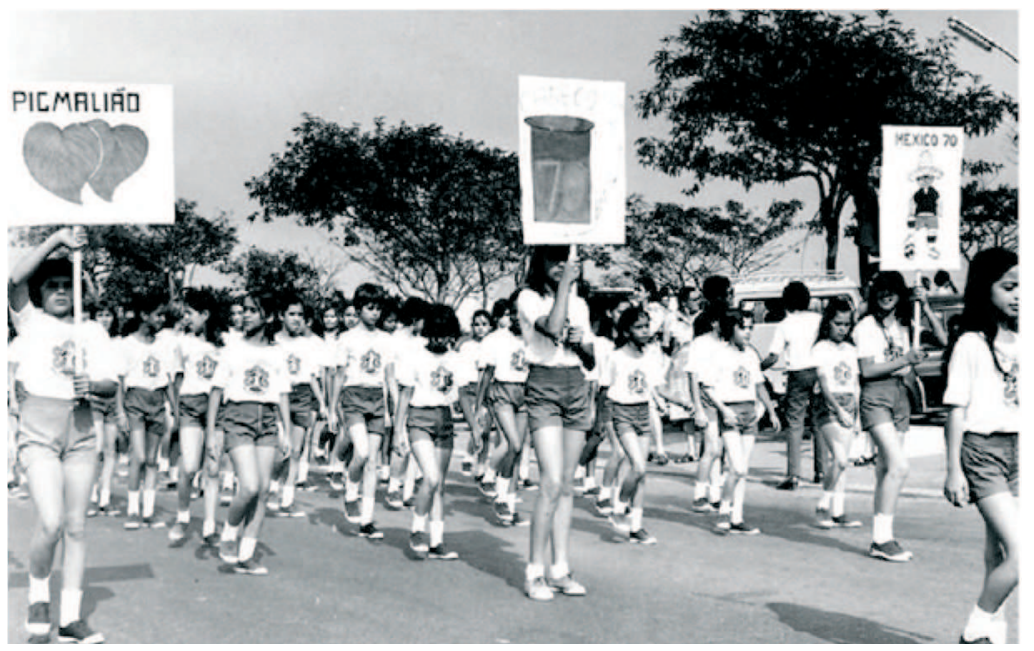

Figura 8 - Fotografia de pelotão em homenagem a vitória do Brasil na Copa do Mundo de Futebol realizada no México

Como vimos, os registros encontrados em nossa pesquisa evidenciaram o esporte como uma prática escolar significativa do currículo da Escola-Parque, ao longo da década de 1960. Segundo Linhales (2006), a partir do início do século XX, notou-se a vulgarização de atividades esportivas no país, que serviram de referência para o que denominou de "forma escolar do esporte". O chamado "surto dos sports", que se propagou no Rio de Janeiro, foi, de acordo com ela, um conjunto de experiências culturais tomadas como conteúdos para a constituição de saberes de uma nova escola, concorrendo para o processo de modernização da educação nacional. O projeto cultural de escolarização do esporte no país, ressalte-se, teria sido promovido pela Associação Brasileira de Educação (ABE).

Observou aquela autora que o esporte contribuiu para o processo socioeducativo protagonizado pela ABE. A entidade almejara a transformação da escola brasileira, marcada naquele período por práticas descontextualizadas, em uma instituição moderna, eficiente e coadunada com o imperativo da industrialização e urbanização. Esse intento justificou ações de caráter disciplinador e moralizante promovidas pela associação, como, por exemplo, eventos cívicos e comemorativos. Dessa forma, dava-se visibilidade pública a comportamentos e con-

Movimento, Porto Alegre, v. 17, n. 01, p. 137-157, janeiro/março de 2011. 
dutas entendidas como modelares para a vida na sociedade moderna. Carvalho (2003, p. 63) acentuou que, nesse contexto, "o esporte e a vida saudável simbolizavam a energia, o vigor, a força, a operosidade, signos de progresso inscritos no corpo que conhece o movimento adequado e útil para cada ato." 14

Essa também parecia ser a visão do próprio idealizador da EscolaParque. No contexto escolar compreendido como uma "comunidade socialmente integrada", a criança se depararia com atividades de estudo, atividades de trabalho e de ação prática, atividades de expressão artística e de fruição do exercício de vida. "Deste modo, praticará na comunidade escolar tudo que na comunidade adulta de amanhã terá de ser: o estudioso, o operário, o artista, o sportsman, o cidadão, enfim, útil, inteligente, responsável e feliz" (TEIXEIRA, 1962, p. 26).

Por um lado, o esporte sofreu uma seleção cultural realizada pela escola, pois, como vimos, antes de impregnar o currículo, já se expressava como prática social significativa no meio urbano em consolidação no país. Os eventos esportivos escolares, por outro lado, expressam uma cultura que busca se disseminar na sociedade a partir da escola. "Nesse movimento, as práticas e os interesses escolares (con)formam a prática de esportes, ao mesmo tempo em que os 'formatos' instituídos no campo esportivo também adentram a escola." (LINHALES, 2006, p. 98).

Outrossim, a educação física na prática curricular da EscolaParque pode ser ilustrada pelas cenas de aulas propriamente ditas. Além das aulas de natação, outras também foram captadas pelo acervo. Na primeira desse conjunto de fotografias, as alunas seguem a professora e executam deslocamento de forma ordenada e ritmada, em pátio coberto da escola (Figura 9). Na segunda as crianças aparecem em coluna, sendo que uma delas segura a bola, no momento de espera para o início da aula ou do jogo (Figura 10). Em ambas se vê a graça das saias de prega, que caracterizaram a farda escolar feminina da época, e, ainda os calções com elástico nas pernas, usados pelas

\footnotetext{
${ }^{14}$ Sob esse aspecto, Schneider e Ferreira Neto (2008) pesquisaram as representações do esporte no Brasil, nas décadas de 1930 e 1940, como padrões culturais do modelo modernizador que o país buscava implantar na política, na sociedade e na economia. Tratou-se de um processo de difusão da cultura Norte-Americana sobre a América Latina que visava à fabricação do "Homem Novo", preparado para atender às contingências das transformações em curso.
}

Movimento, Porto Alegre, v. 17, n. 01, p. 137-157, janeiro/março de 2011. 
meninas durante as aulas de educação física. Notamos, nesse caso, ao contrário das aulas de natação, que a turma era composta apenas de meninas, tendo se aplicado o critério da formação de turmas por separação por sexo.

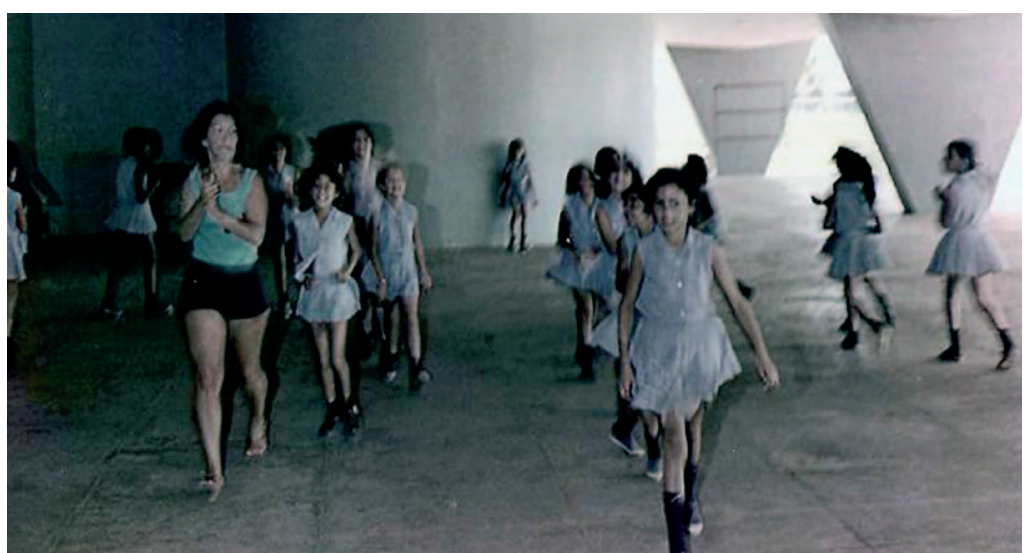

Figura 9 - Fotografia de aula de educação física orientada por uma professora, no espaço sombreado da pérgula do prédio principal. O conjunto de pilotis em formato de triângulo e o teto anguloso caracterizam a arquitetura modernista da escola.

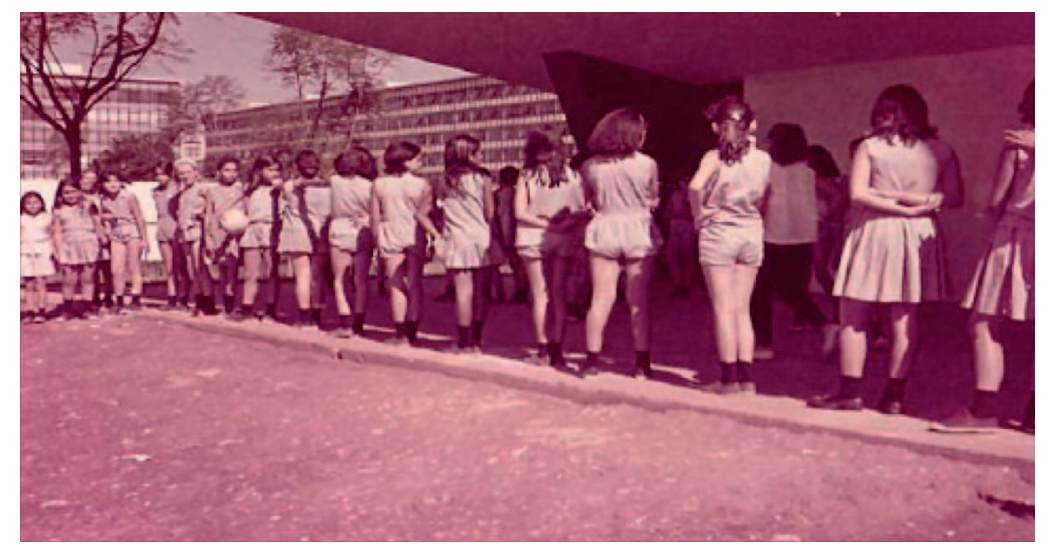

Figura 10 - Fotografia de meninas em formação de coluna na aula de educação física.

Movimento, Porto Alegre, v. 17, n. 01, p. 137-157, janeiro/março de 2011. 


\section{ConsideraçõES FINAIS}

As imagens de aulas na Escola-Parque são uma referência do processo histórico de sistematização, que a educação física vem percorrendo na escola brasileira desde o século XIX, passando de atividades genéricas a práticas sistematizadas e, finalmente, tornando-se uma atividade do currículo obrigatório nacional, em 1971, conforme o Decreto No 5.692/71. Tais evidências podem ser interpretadas como um aspecto inovador, que caracterizou o projeto moderno de renovação pedagógica, pois tradicionalmente a escola se limitava a instruir as crianças nas primeiras letras e nas quatro operações - ler, escrever e contar. Além disso, como destacamos anteriormente, a educação física não se encontrou isolada naquele projeto. A sua inserção ao lado de atividades artísticas fez dela um componente de um repertório curricular amplo, cuja abrangência sugere experiências formativas de caráter aberto e lúdico.

No que concerne à história das Escolas-Parque de Brasília, até hoje não foram edificadas todas as unidades previstas ${ }^{15} \mathrm{e}$, além disso, outros aspectos denotam uma ruptura com a concepção original ao longo de sua trajetória de cinquenta anos. Entre eles, destacamos a interrupção da oferta do ensino integral pela rede pública e a fragmentação do currículo. A Escola-Parque, embora continue em funcionamento, deixou de concentrar aquela comunidade de educação completa vislumbrada no projeto de Brasília, dando lugar ao ensino disciplinar, principalmente de Educação Física e de Educação Artística.

As fotografias observadas, além de abrir uma janela para o passado, servem como um testemunho visual da proposta original para a educação escolar em Brasília. Sobretudo as fotografias nos permitem constatar uma nova relação pedagógica em curso. A nova relação pedagógica da Escola-Parque se baseava, como vimos ao longo do texto, em um projeto curricular alternativo, bem como no turno integral e em uma arquitetura escolar especialmente planejada.

${ }^{15}$ Foram construídas até hoje em Brasília apenas cinco Escolas-Parque, de um total de vinte e oito que haviam sido planejadas.

Movimento, Porto Alegre, v. 17, n. 01, p. 137-157, janeiro/março de 2011. 
Além disso, levando em conta nossos objetivos de pesquisa, uma característica se destacou na análise do currículo em tela, ou seja, a presença e a intencionalidade de uma educação do corpo como parte da pedagogia escolar, que deram ensejo à valorização da educação física como atividade escolar.

Movimento, Porto Alegre, v. 17, n. 01, p. 137-157, janeiro/março de 2011. 
School physical education in Brasília, in the 1960s

Abstract: The research aimed to analyze physical education activities present in the original curriculum of the School-Park Brasilia in the 1960s. The cultural history was used as a reference theoretical, focusing on the treatment of primary sources such as photographs, official documents, interviews and publications of the time. The sources revealed that physical education was realized in the form of recreation, sports, competitions, shows and classes, occupying a prominent place in the school culture analyzed. The physical education activities were part of an innovative educational project whose design tools, enhanced curriculum, architecture and integral part signified education of the body. Key words: Physical Education. Education. History. Photography.

\begin{tabular}{|l|}
\hline Educación Física en la escuela, en los anõs 60 \\
La investigación tubo como objetivo analizar las activi- \\
dades de educación física que tuvieron lugar en el plan \\
de estudios original de la Escuela-Park de Brasília en \\
la década de 1960. La historia cultural se utilizó como \\
referencia teórico-metodológica el tratamiento de las \\
fuentes primarias tales como fotografías, documentos \\
oficiales, entrevistas y publicaciones de la época. Las \\
fuentes revelaron que la educación física se realizó \\
en la forma de recreación, deportes, concursos, es- \\
pectáculos y clases, que ocupa un lugar prominente \\
en la cultura escolar analizada. Las actividades de \\
educación física eran parte de un proyecto educativo in- \\
novador, cuyo diseño educativo, programas de estudios \\
ampliado y la existencia de un proyecto arquitectónico \\
distinto contribuyen para la valorización de una edu- \\
cación del cuerpo. \\
Palabras clave: Educación Física. Educación. Historia. \\
Fotografía.
\end{tabular}

\section{REFERÊNCIAS}

BENJAMIN, Walter. Magia e técnica, arte e política: obras escolhidas. 3. ed. São Paulo: Brasiliense, 1987.

BRASIL. Estado Maior das Forças Armadas. Escola Superior de Guerra. Brasília: plano educacional e médico-hospitalar. Brasília, 1959.

Movimento, Porto Alegre, v. 17, n. 01, p. 137-157, janeiro/março de 2011. 
CARVALHO, Marta M. Chagas de. A escola e a república e outros ensaios. Bragança Paulista: EDUSF, 2003.

DUARTE, Maria de Souza. A educação pela arte: o caso Brasília. Brasília: Thesaurus, 1983

ESCOLA-PARQUE 307/308 SUL. 1960-1972. 1 álbum (226 fot.): pr. e br. e color.

DISTRITO FEDERAL. Secretária de Educação e Cultura. A escola-parque em Brasília. Brasília, [197-].

HOBSBAWM, Eric. Sobre história. São Paulo: Companhia das Letras, 1998.

JULIA, Dominique. A cultura escolar como objeto histórico. Revista Brasileira de História da Educação, Campinas, n. 1, p. 9-43, jan./jun. 2001.

KISHIMOTO, Tizuko Morchida. Jogos infantis: o jogo, a criança e a educação. 6. ed. Petrópolis: Vozes, 1999.

LE GOFF, Jacques. A história nova. São Paulo, Martins Fontes, 1995.

LEITE, M. L. M. Imagens e contextos. Boletim do Centro de Memória Unicamp C.M.U., v. 5, n. 10, p. 45-60, 1993.

LINHALES, Meily Assbú. Produção de uma forma escolar para o esporte: os projetos culturais da Associação Brasileira de Educação (1926-1935) como indícios para a historiografia da educação física. In: OLIVEIRA, Marcus Aurélio. Educação do corpo na escola brasileira. Campinas: Autores Associados, 2006. p. 93-110.

LOIZOS, Peter. Vídeo, filme e fotografias como documento de pesquisa. In: BAUER, Martin W.; GASKEL, George. Pesquisa qualitativa com texto, imagem e som: um manual prático. Petrópolis: Vozes, 2002. p. 137-155.

Martin W.; GASKEL, George. Pesquisa qualitativa com texto, imagem e som: um manual prático. Petrópolis: Vozes, 2002. p. 137-155.

OLIVEIRA, Marcus Aurélio Taborda. A título de apresentação - educação do corpo na escola brasileira: teoria e história. In: . Educação do corpo na escola brasileira. São Paulo: Autores Associados, 2006. p. 1-34.

PEREIRA, Eva Wairos; ROCHA, Lúcia Maria da Franca. Anísio Teixeira e o plano de educação de Brasília. In: REUNIÃO ANUAL DAANPED 28.. 2005. Anais... Disponível em: <http://www.anped.org.br>. Acesso em: 10 maio 2006.

RABELLO, Branca. 1981. Entrevista concedida a Maria de Souza Duarte.

SILVA, Ernesto. [Entrevista]. Entrevista concedida a Luciana de Maya Ricardo. 2006.

SOUZA, Rosa Fátima de. Fotografias escolares: a leitura de imagens na história da escola primária. Educar, Curitiba, n. 18, p. 75-101, 2001.

Movimento, Porto Alegre, v. 17, n. 01, p. 137-157, janeiro/março de 2011. 
SCHNEIDER, Omar; FERREIRA NETO, Amarílio. Americanismo e a fabricação do "homem novo": circulação e apropriação de modelos culturais na Revista Educação Physica (1932-1945). Movimento, Porto Alegre, v. 14, n. 1, p. 135-159, jan./abr. 2008.

TEIXEIRA, Anísio. Centro educacional Carneiro Ribeiro. Revista Brasileira de Estudos Pedagógicos, Brasília, v. 31, n. 73, p. 78-84, jan./mar. 1959.

Plano de construções escolares de Brasília. Revista Brasileira de Estudos Pedagógicos, Brasília, v. 35, n. 81, p. 195-199, jan./mar. 1961.

Uma experiência de educação primária integral no Brasil. Revista Brasileira de Estudos Pedagógicos, Brasília, v. 38, n. 87, p. 21-33, jul./set. 1962.

THOMPSON, E. P. Agenda para uma historia radical. Barcelona: Crítica, 2000.

TROIS, Stella dos Cherubins. [Entrevista] Entrevista concedida a Maria de Souza Duarte. 1981.

VIANA FILHO, Luís. Anísio Teixeira: a polêmica da educação. 3. ed. São Paulo: UNESP; Salvador: EDUFBA, 2008.

VIEIRA, Maria do Pilar de Araúlo; PEIXOTO, Maria do Rosário da Cunha; Yara Maria Aun Khoury. A pesquisa em história. São Paulo: Ática, 1998.

VINÃO FRAGO, Antonio. Historia de la educación e historia cultural: posibilidades, problemas, cuestiones. Revista Brasileira de Educação, São Paulo, n. 0, set./ dez. 1995.

Wovimento, Porto Alegre, v. 17, n. 01, p. 137-157, janeiro/março de 2011. 